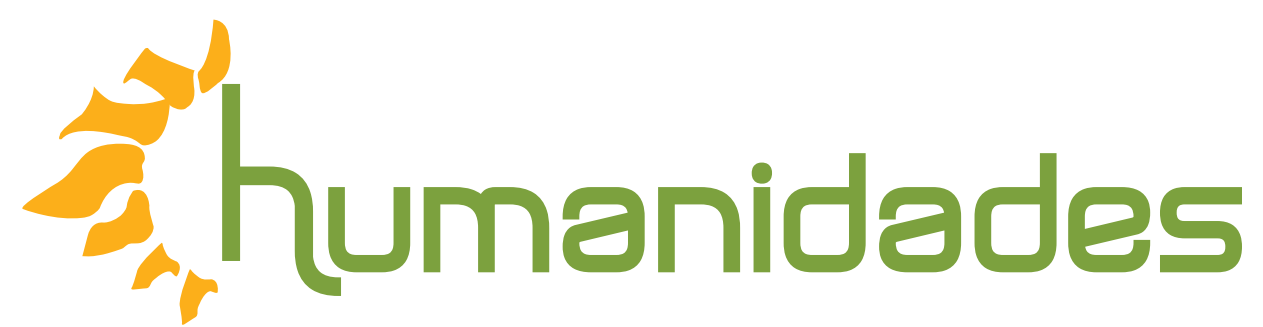

Revista humanidades

Enero-Junio, 2015 • Volumen 5, Número 1 • ISSN 2215-3934 • pp. 1-23

\title{
El crudo despertar de Lázaro de Betania
}

DOI: http://dx.doi.org/10.15517/h.v5i1.19382

Recibido: 28-Marzo-2015 / Aceptado 13-Abril-2015

\section{Grettel Mariana Arias Orozco}

Licenciada, profesora interina en la Facultad de Educación de la Universidad de Costa Rica y profesora de Español en el Ministerio de Educación Pública.

Correo electrónico: arias.grettel@gmail.com

Más sobre el autor:

Todos los derechos reservados. Universidad de Costa Rica. Esta revista se encuentra licenciada con Creative Commons Reconocimiento-NoComercial-SinObraDerivada 3.0 Costa Rica.

Correo electrónico: humanidades.eeg@ucr.ac.cr / Sitio web: http:/ / revistas.ucr.ac.cr/index.php/humanidades 


\section{El crudo despertar de Lázaro de Betania}

\section{Resumen}

En este escrito se discute cómo el personaje principal de la novela costarricense El despertar de Lázaro (2003) de Julieta Pinto, rompe con el eterno silencio del personaje bíblico, con lo cual se deconstruye el relato bíblico y se logra percibir a Lázaro como a una persona real, de "carne y hueso". Asimismo, experimenta un doble exilio, en tanto una vez muerto es forzado a regresar a la vida; ya no pertenece a la vida ni a la muerte. Como resultado, este personaje literario se instaura como el otro o la alteridad inaceptable.

\section{The difficult waking up of Lazarus of Bethany}

\begin{abstract}
This paper discuss how the principal character of the Costa Rican novel $E l$ despertar de Lázaro (2003) of Julieta Pinto tears up the eternal silence of the biblical character, which allows to deconstruct the biblical tale and to perceive Lazarus as a real person in "blood and flesh". Additionally, he experiences a double exile, as once dead he is forced to come back to life; due to this he no longer belongs to life nor to death. As a result, this literary character is built as the other or the unacceptable otherness.
\end{abstract}

Palabras clave:

Lázaro de Betania, Jesús, muerte, resurrección, exilio.
Keywords:

Lazarus of Bethany, Jesus, death, resurrection, exile. 
Jesús levantó los ojos al cielo y exclamó: “Te doy gracias, Padre, porque has escuchado mi oración. Yo sé que siempre me oyes. Pero hablé por los que están aquí, para que crean que tú me has enviado”. Al decir esto, gritó muy fuerte: ¡Lázaro, sal fuera! Y salió el muerto. Tenía las manos y los pies vendados, y la cabeza cubierta con un velo, por lo que Jesús dijo: "Desátenlo y déjenlo caminar".

(Juan 11, 11)

La muerte es un problema que concierne especialmente al ser humano. Por ello, ha sido tema de meditación en la historia, la ciencia, el arte, la literatura, así como otras formas de expresión a lo largo de la humanidad. De allí que el reflexionar sobre el tema de la muerte, también implica analizar la vida misma. Lo cierto es que la muerte está presente en cada ser viviente, es inherente a la vida.

Por esta razón, la novela El despertar de Lázaro (2003) de la escritora costarricense Julieta Pinto es de gran interés para el lector, pues expone temas que atañen a la raza humana que tanto ha tratado de comprender este proceso que le es ineludible. De esta forma, encontramos una nueva perspectiva ante la vida, y ante la muerte misma, debido a que no existe una sin la otra. Como lo señala Sciacca (1962) "la hora de la muerte está en cada hora de nuestra vida: la vivimos durante toda la existencia y no sólo el último día. La muerte teje la trama de la vida; cada día, cada hora, cada minuto puede ser siempre el último; está inscrita en nuestra historia y le es esencial" (p. 22).

Ante este hecho, nace el sueño de la inmortalidad, donde la muerte ya no es causa de temor. La mayoría buscan y anhelan cumplir esta ilusión a través de la figura de Dios, en el acontecimiento de la resurrección propiamente. Sin embargo, qué sucede si, como el Lázaro de Julieta Pinto, la resurrección no es la verdadera salvación, pues quien ha estado en las tinieblas ya no puede formar parte de la luz de la vida de nuevo y que, como lo expresa Cristina Peri Rossi ${ }^{1}$ en uno de sus poemas: 
No, nadie te esperó, nunca.

No te esperaron los árboles

que habías plantado

ni la estatua del indio herido

en bronce enmohecido

No te esperó tu tía abuela

que murió llamándote...

El mar no espera nunca

$\mathrm{Y}$ en su ir y venir...

No hay retorno:

el espacio cambia

el tiempo vuela

todo gira en el círculo infinito

del sinsentido atroz.

No quiero volver...

Quiero otra luz, otro mar,

otras voces, otras miradas

romper este pacto de nostalgia

que nos ata, como una condena de una maldición...

No hay volver...

Sólo la soledad es igual a sí misma.

(Estado de exilio $\left.{ }^{2}, 2003\right)$ 
Por ello, este texto literario costarricense constituye una puerta a la reflexión sobre la vida, la muerte y lo que nos espera después de esta. Pero sobre todo, es una puesta en escena al evento de la resurrección, ya no vista desde la forma estilizada e ilusoria que presenta la Biblia, sino como un hecho real, congruente y cruel. Es el despertar de un hombre después de haber estado cuatro días en el sepulcro descomponiéndose contra su voluntad y su sentir-sufrir sobre ello.

El intertexto inmediato de El despertar de Lázaro (2003) es el presente en el Nuevo Testamento escrito por San Juan. El Lázaro descrito en la Biblia es uno de los personajes más misteriosos y enigmáticos, pero Julieta Pinto logra ahondar aún más en sus adentros, hasta mostrar qué es realmente lo que siente con respecto a su ida a

El silencio de Lázaro las tinieblas y su retorno.

Para Enrique Martínez Fernández (2001), la intertextualidad es la característica inherente de todo texto al poseer un carácter dinámico, heterogéneo y estar siempre abierto al diálogo con otros textos. Indica que no es algo único ni autónomo, ni mucho menos, cerrado en sí mismo, sino que:

La intertextualidad se genera, según Kristeva, todo desde el eje horizontal o sintagemático como desde el vertical o para paradigmático; en el primero, la palabra pertenece a la vez "ausujet de l'ecriture et audestinataire" (Kristeva, 1969, 145); en el eje vertical, la palabra del texto se relaciona con otras de textos anteriores (es el eje de la selección y la permutación) (p. 57).

Por ello, considera que la intertextualidad opera en un contexto histórico y sociocultural. Además, asegura que el texto literario no se legitima con su corporeidad o en su singularidad, sino por estar escrito "desde, sobre y dentro de otros textos", pues como exponía Kristeva "se construye como un mosaico de citas, todo texto es absorción y transformación de otros textos [...]" (2001, p. 74). De esta manera, en este caso particular, el relato bíblico se configura como el intertexto de la novela costarricense en estudio. 
Esta versión bíblica que sirve de intertexto, expone la posición tradicional y "oficial" de la historia, donde Lázaro se caracteriza por la eterna ausencia de palabra. Lázaro por naturaleza comulga con un eterno silencio, mutismo que refleja, claramente, el anonimato de una palabra que ha renunciado a hacerse reconocer. $\mathrm{La}$ convencional ausencia de su palabra se manifiesta, entonces, mediante un discurso donde el sujeto, es decir Lázaro, es hablado por los otros, siempre asumido a partir de las palabras de los demás, más que por las propias.

No obstante, el Lázaro de Julieta Pinto se niega a asumir como propias las características que le han sido otorgadas por aquellos que lo comunican. Razón por la cual, la voz que Julieta Pinto le otorga a este personaje bíblico es tan atrayente, y a la vez, controversial, pues rompe con las ataduras en que se instaura el dogmatismo cristiano. Rasgo que configura El despertar de Lázaro (2003) como un texto literario deconstructivo y subversivo a la vez.

Al respecto, Jonathan Culler (1984) señala que la deconstrucción se basa en la inversión de jerarquías por medio de una "doble acción, un doble silencio, una escritura doble, poner en práctica una inversión de la oposición clásica y un corrimiento general del sistema [...] El practicante de la deconstrucción opera dentro de los límites del sistema, pero para resquebrajarlo” (párr. 2). Se trata, concretamente, de acabar con las concepciones y los mitos de la palabra original, de la plenitud del ser, del sentido y de la presencia.

Peretti della Rocca (1989) agrega que el fonocentrismo hace referencia a la caracterización que se hace del lenguaje como foné o "viva voz", lo cual implica que:

[...] el sistema fonocéntrico requiere que la voz sea oída inmediatamente por el que la emite. El oírse-hablar no es otra cosa que la conciencia de sí, la presencia a sí de la conciencia que se habla/se oye a sí misma 
inmediatamente de viva voz: la presencia del sentido a la conciencia de sí. La voz se da a la conciencia como íntimamente ligada al pensamiento del concepto significado. La voz, elemento de proximidad a sí, aparece como la conciencia misma. El privilegio de la conciencia es la posibilidad de viva voz, expresión que dice el lazo que une foné, logos y presencia (p. 34).

De este modo, se busca determinar de qué manera Lázaro se percibe como un personaje que invierte las jerarquías establecidas y habita las oposiciones. Así, en esta novela costarricense, a un personaje periférico, sin mayor valor por sí mismo, se le otorga la voz, la palabra. Por ello, logra revertir su posición y "descabrajar" la historia oficial, tomando en consideración que, como indica Culler (1984), "paradójicamente, cuanto más poderosa y autorizada sea una interpretación, mayor será la cantidad de escritos que genere" (párr. 17).

Ciertamente, el Lázaro de Julieta Pinto no es el Lázaro de la Biblia que no dice ni comenta nunca nada sobre un hecho tan trascendental como la resurrección, sino que se presenta en el texto de la escritora costarricense, el reflejo de un ser humano pleno que hace uso de su palabra, animada y vital, quien se hace dueño de su palabra para utilizarla como un arma de constante reproche.

Perdido en mis meditaciones no escuché su llegada. Sus palabras me sobresaltaron. Callé, como he callado siempre. No puedo hablar de lo que está oculto, de lo que yo mismo no descubrí sino hasta que la vida fue un recuerdo y los hechos pasados se presentaron con toda nitidez (Pinto, 2003, p. 15).

De esta forma, se contrapone la visión de los cristianos sobre la vida después de la muerte, con la que Lázaro nos narra. De acuerdo con los cristianos, el morir conlleva, como consecuencia inevitable, la permanencia eterna en el Cielo o en el 
Infierno, según haya vivido cada persona. Así, únicamente aquellos que sigan el camino trazado por Jesús, único Señor y salvador, alcanzarán la redención a través de la gracia máxima: la resurrección.

No obstante, la confesión que ofrece el protagonista de Julieta Pinto es en todo momento de protesta, duda y reproche. No desea ser parte de un plan divino que no comprende y al cual nunca fue invitado a participar, mismo que lo excluye del mundo al que perteneció y niega todo lo que una vez deseó: "Maldigo una y mil veces el día en que lo conocí; maldigo su intromisión en mi vida. ¿Por qué me involucró en su destino si yo jamás se lo pedí?" (Pinto, 2003, p. 55).

Explica Pedro Herrasti ${ }^{3}$ en El cristiano ante la muerte (2008) que la muerte es trágica, pues el hombre, un ser viviente, se enfrenta con la muerte, que es "la contradicción de todo lo que un ser humano anhela: proyectos, futuro, esperanzas, ilusiones, perspectivas y magníficas realidades" (párr. 9). Es una realidad irremediable que expone "la debilidad e impotencia del hombre". Solo queda el despojo de lo que fuimos: un cadáver.

Esta situación provoca en los familiares y la comunidad cristiana un clima muy complejo. El cuerpo del muerto genera preguntas, cuestiones insoportables. Nos enfrenta ante el sentido de la vida y de todo, causa un dolor agudo ante la separación y el aniquilamiento. Todo el que haya contemplado la dramática inmovilidad de un cadáver no necesita definiciones de diccionario para constatar que la muerte es algo terrible.

Ese ser querido, del que tantos recuerdos tenemos, que entrelazó su vida con la nuestra, es ahora un objeto, una cosa que hay que quitar de en medio, porque a la muerte sigue la descomposición. Hay que enterrarlo. Y después del funeral, 
al retirarnos de la tumba, vamos pensando con Bécquer: "iQué solos y tristes se quedan los muertos!” (Herrasti, 2008, párr. 4 y 5).

Realidad que personifica el Lázaro de Julieta Pinto, pues declara que de ninguna forma puede ser posible que la muerte sea necesaria para que el amor exista porque ambas concepciones se oponen diametralmente; así sólo la vida puede ser amor.

No quería oír más, ni saber nada de un amor contradictorio que anula la vida y deja sólo la esperanza. Ellos, sus discípulos, pueden creerle porque no saben lo que es la muerte. Estoy seguro de que Jesús, en cuanto sienta los ojos y oídos sellados por el polvo y no pueda franquear el muro del silencio, se arrepentirá de haber ofrendado su vida (Pinto, 2003, p. 28).

Para el cristiano verdadero, sin embargo, la muerte no es el fin, sino que, por el contrario, es el principio de la vida eterna que se alcanza en la resurrección gracias al amor de Dios y su hijo Jesús por la humanidad. Así lo expone Pedro Herrasti (2008), quien indica que los humanos llevamos en nuestro cuerpo la sentencia de muerte debido al pecado original, pero tanto nuestra alma como el cuerpo resucitarán para la eternidad, lo cual es afirmado también por San Pablo en el Nuevo Testamento:

Mas ustedes no son de la carne, sino del Espíritu, pues el Espíritu de Dios habita en ustedes. El que no tuviera el Espíritu de Cristo, no sería de Cristo. En cambio, si Cristo está en ustedes, aunque el cuerpo vaya a la muerte a consecuencia del pecado, el espíritu vive por estar en Gracia de Dios. Y si el Espíritu de aquel que resucitó a Cristo de entre los muertos está en ustedes, el que resucitó a Jesús de entre los muertos dará también vida a sus cuerpos mortales; lo hará por medio de su Espíritu, que ya habita en ustedes. (Romanos 8, 9-11) 
De esta manera, para el cristiano creyente la muerte llega a hacerse deseable, en tanto representa un encuentro con el Señor Salvador y la vida eterna. Para el Lázaro de Julieta Pinto, no obstante, la muerte constituye la negación del ser, lo cual es reafirmado por el eterno silencio de Lázaro y el hecho de que ya nunca será quien solía ser cuando aún era uno más de los seres vivientes.

Se trata de un viaje sin retorno el que experimenta Lázaro de Betania, el cual él no logra finalizar y del que nunca debió regresar. Viaje que es obligado a realizar, y es forzado también a finalizar por el mismo actor: Jesús de Nazaret, el culpable de todos sus males.

El exilio que sufre tanto el Lázaro de la Biblia como el de la escritora costarricense no es uno común, ambos son enviados a la misma muerte, a la incertidumbre del más allá. Al regresar, el Lázaro de la Biblia nunca pronuncia palabra alguna sobre lo experimentado, pero el Lázaro de Julieta Pinto explota, se enfurece, se frustra ante lo perdido pero, ante todo, comprende que ya no es uno más de los seres vivos. Ahora, añora el volver a la quietud de las tinieblas que es equivalente, a la vez, a la luz que no logró alcanzar: "De rodillas ruego a la tierra que me reciba, misericordiosa, y me incorpore a ese suelo de silencio gris; que acoja mi cuerpo, ahora que Jesús ya no puede arrebatárselo" (Pinto, 2003, p. 95).

Claramente, este viaje que es impuesto a Lázaro por Jesús es al exilio de la muerte. De esta forma, debe abandonar su hogar, sus seres queridos, sus añoranzas e ilusiones, e incluso, se ve forzado a renunciar a su propio ser. Él es un exiliado, lo cual significa, según Peri Rossi (2003), que ya no es, ha dejado de ser, ha perdido su identidad. Dice la autora que la misma etimología de la palabra "exilio" es muy clara y expresiva:

[...] ex significa, precisamente, quien ya no es, ha dejado de ser. Es decir, quien ha perdido toda o parte de su identidad. El exilio cuestiona, en primer lugar, la identidad, ya que desvincula de los orígenes, de la historia particular 
de una nación, de un pueblo, desvincula de una geografía, tanto como de una familia, de una calle, de una arboleda o de una relación sentimental [...] (2003, p. 7).

Es desde su mirada de exiliada que se comprende lo que sucede con Lázaro después de su resurrección. De este modo, es posible equiparar la muerte con el exilio, pues son dos formas diferentes de un mismo sentimiento, un mismo desgarramiento: "No fue fácil morir, desprenderme del aire, del color, del sonido, y caer en la nada me provocó el terror de no ser; me aferré a la agonía durante muchas horas. Fue una lucha de todo mi ser que solo se aquietó al sucumbir" (Pinto, 2003, p. 18).

Es desde esta visión que se analiza la tragedia del Lázaro de Julieta Pinto. Así, el dilema del exilio no termina aquí, sino que sólo es el comienzo, pues al ya no pertenecer al lugar natal y lograr regresar después de un período largo o breve de tiempo (lo cual sería considerado como una gran alegría), se hace evidente que ya tampoco se pertenece allí. No se es de allá ni de aquí, lo cual es claramente lo que vive Lázaro.

La muerte de Lázaro constituye una prueba del poder divino que habita en Jesús. Por ello, Lázaro lo señala como único culpable de todos sus males, pues él frustró su vida y su muerte. Pudo sanarlo cuando aún estaba con vida, cuando Lázaro aún luchaba exasperadamente por vivir, pero decidió aprovechar la oportunidad para demostrar que le había sido otorgada la gracia de Dios.

Le pidieron mi resurrección y no sólo complació su fe sino que aprovechó la oportunidad para demostrar que le había sido otorgada la gracia de Dios. Pudo haberme sanado cuando me debatía en el horror de la agonía, cuando mi cuerpo hacía esfuerzos desesperados por vencer la invasión de la muerte y mis ojos y labios imploraban la vida. Si realmente me hubiera amado, mi 
juventud no se habría destrozado al caer en el profundo tiempo del dolor, entre la duda de vivir o de morir. Lo odio por todo ese daño irreparable [....] (Pinto, 2003, p. 14).

El exilio es de por sí una terrible experiencia humana, pero aún más lo es el que sufre Lázaro, quien debe enfrentar las tinieblas de la incertidumbre y de lo desconocido para iniciar su viaje a la muerte. Al respecto, afirma Cristina Peri (2003) que el exilio es como una castración, pues la castración con todas sus metáforas es el fantasma que cualquier pérdida pone en evidencia. Este sentimiento de pérdida, de derrota y de ruptura es el que atormenta a Lázaro constantemente.

A veces preferiría marcharme

El espacio me angustia como a los gatos

Partir

es siempre partirse en dos.

(Estado de exilio, 2003)

Es en este punto cuando Lázaro es llamado por Jesús para que se levante de entre los muertos, lo cual impide que complete el periplo dolor- castración- integraciónamor que, de acuerdo con Peri Rossi (2003, p. 9), experimenta todo exiliado. De este modo, logra vivenciar el dolor de su viaje al exilio y la castración que este implica, pero no consigue alcanzar las dos últimas etapas del proceso de reconciliación, la integración y el posterior amor, que son los que le hubiesen permitido formar parte de una nueva vida.

[...] sé que arruinó mi vida desde que me arrancó de la muerte (Pinto, 2003, p. 16). 
Y más adelante continua Lázaro con su reproche:

[...] nunca quise morir; nunca quise sacrificar mi única vida. Fue injusto habérmela arrebatado y más injusto darme otra, mustia y quebrada (Pinto, 2003, p. 18).

Comenta Cristina Peri Rossi (2003) que todo exilio es diferente pero todos tienen en común la nostalgia, razón primordial por la que no se puede abandonar la segunda vida para regresar a la primera. Por ello, una vez que se ha experimentado el exilio no hay vuelta atrás, ya que sería repetir la experiencia de añoranza; es vivir una nueva nostalgia (2003, p. 10).

$$
\begin{gathered}
\text { Soñé que volvía } \\
\text { pero una vez allí } \\
\text { tenía miedo } \\
\text { y quería irme } \\
\text { a cualquier otro lado }
\end{gathered}
$$

(Estado de exilio, 2003)

Este sentimiento lo personifica Lázaro al expresar reiterativamente sus anhelos truncados por conocer la vida que le aguardaba después de la muerte: “[...] a veces recuerdo la luz que vislumbré, antes que Él dijera mi nombre y creo que esa luz es el principio del camino hacia el Padre [...]" (Pinto, 2003, p. 62).

En la cita anterior se demuestra la frustración de Lázaro por no haber alcanzado la muerte a causa del llamado de la resurrección. Jesús trunca su proceso de reconciliación y su "camino hacia el Padre" como lo define él mismo. Por tanto, Lázaro ya no la ve la muerte desde la mirada de un ser viviente. En él no hay temor ni ansiedad por el sueño eterno. 
En definitiva, el estado anterior en el que se encontrada antes de ser levantado del sepulcro no era funesto ni aterrador, sino más bien considera que: "[...] la muerte es la liberación de todo lo que nos limita en la tierra, de todo lo que ha impedido la realización de mi existencia terrestre" (Pinto, 2003, p. 127). Por consiguiente, Jesús de Nazaret no le ha brindado la salvación al resucitarlo, por el contrario, es un castigo que lo atormenta constantemente al darse cuenta que no pertenece a ningún lugar.

Lázaro de Betania recuerda el funeral de su padre y como su hermana Marta lo toma de la mano para consolarlo. Le lleva hacia un montón de flores rojas y le cuenta que dentro de unos días la tierra trasformará el cuerpo de su padre en raíces, después en tallos, y por último, surgirá de la tierra en flores como aquellas. Ante tal recuerdo Lázaro sufre aún más, pues sabe que a él la tierra lo desterró y de su cuerpo no nacieron flores rojas:

Extiendo la mano tímidamente y acaricio la tierra. Es un ruego a sus entrañas, a esas capas del tiempo superpuestas en el residuo de los siglos. Yo fui expulsado de su seno al cabo de tres días. La tierra vomitó mi cuerpo, amargo de rencor, en vez de asimilarme a sus corrientes subterráneas. Y yo, que deseaba ser semilla, quedé convertido en despojo (Pinto, 2003, p. 129).

Al no alcanzar la cúspide, su ser se debate entre la esperanza de lo que le esperaba después de la muerte, y el inmenso temor que siente ante la muerte y una posible nueva resurrección: "Quisiera saber si al morir de nuevo alcanzaré por fin la luz, pero me detiene el horror de mis últimos minutos, la incertidumbre de lo que encontraré" (Pinto, 2003, p. 26).

Además, asegura Peri Rossi (2003, p. 10) que lo más importante, a veces, no es sobrevivir, sino cómo, porque hay formas de sobrevivir que no valen la pena, ya que nos dejan sin principios, sin identidad; pensamiento que expresa Julieta Pinto espléndidamente en su obra: 
Yo quedo postrado, lleno de reminiscencias, frustraciones, desengaños, maldigo a Jesús por haberme dado esta vida seca, desértica, sin esperanza (Pinto, 2003, p. 83).

[...] La tumba, el encierro, el espacio vacío repleto de oscuras humedades y asquerosos gusanos, fueron los que mutilaron mi ser [...] (Pinto, 2003, p. 93).

Es en este punto cuando se hace notorio que tras el exilio y el posterior regreso de Lázaro a la vida, él ha dejado de ser alguien más del montón, ahora es diferente, es único. Lázaro es un muerto entre los vivos. Acontecimiento que trunca y desgarra su ser. Lo que nos presenta Julieta Pinto en su texto literario son los despojos del hombre que alguna vez fue Lázaro de Betania.

De acuerdo con Villoro (1998), la alteridad se refiere al conjunto de seres humanos o aspectos culturales que no pertenecen a mi grupo, lo cual produce inquietud y preocupación ante ese otro que nos es totalmente ajeno y diferente. Lo otro, lo incomprensible, lo desconocido, lo fascinante y lo terrible, al mismo tiempo, es la muerte. Es por este hecho que el resucitado es el arquetipo de dudas, de angustias y de temores; es "el mayor extranjero que pueda existir" (Jones, 2008). Así, a través de la mirada de los demás se escudriña y se teme su presencia. Triste, derrotado, nostálgico, enfermo y desamparado retorna Lázaro de la muerte.

Como se mencionó anteriormente, el exilio de Lázaro no es uno cualquiera. Se trata de un exilio hacia la muerte, la cual ha sido la incógnita por excelencia del hombre a lo largo de todos los tiempos. Por consiguiente, al regresar de la muerte, Lázaro se constituye como una presencia enigmática y extraña, pero a la vez cercana e íntima. Representa ahora el paradigma de la muerte, lo cual genera inquietud y preocupación en los demás que lo sienten totalmente ajeno y diferente. Lázaro es el otro. 
En mí, el regreso de la muerte destruyó la esperanza; las memorias de la infancia se confunden con el camino recorrido después de mi muerte. No debo mezclarme con los seres humanos, ya no pertenezco a su especie, soy un híbrido, algo que oscila entre lo que es y lo que no es, entre lo palpable y lo etéreo (Pinto, 2003, p. 58).

Para Villoro (1998) el sistema de creencias de toda cultura se basa en la forma de ver el mundo que se establece a partir de ciertos valores y categorías básicas, en un intento por comprender al otro. A partir de esta ideología existen, principalmente, tres niveles del reconocimiento del otro como sujeto, donde puede ser visto como alguien inferior, igual o superior a mí.

Todas las culturas comprenden ciertas creencias básicas, presupuestas en todas las demás, que no pueden ponerse en cuestión sin minar la imagen del mundo de esa cultura. Esas creencias básicas, poco precisas y a menudo inconscientes, se muestran en las más diversas actitudes y comportamientos de los miembros de esa cultura. Pueden llegar a expresarse en conceptos, pero también en imágenes y en sentimientos compartidos. Constituyen el núcleo de la "figura" que una cultura se forma del mundo y del hombre, el marco en el que se encuadran sus creencias y actitudes. Para comprender cualquier hecho nuevo, una cultura debe poder encuadrarlo en ese marco (p. 176).

Pues bien, el encuentro entre Lázaro y la civilización humana es el mejor ejemplo de la enorme dificultad que puede encarar una cultura por rebasar su propio marco de creencias básicas para respetar y aceptar las de la otra cultura. Entonces, frente a esta alteridad extrema, que simboliza Lázaro, cada una de las partes trata de comprenderse a partir de su propio marco cultural para lograr integrar la otra parte en su propia figura de mundo. 
Empresa que en este caso resulta inútil, pues el reconocimiento que se lleva a cabo del otro, es decir, de Lázaro, se realiza desde el primer nivel que describe Villoro (1998), el cual consiste en traducir la otredad del otro a partir de objetos y situaciones conocidos en nuestro propio mundo que caen bajo las categorías y valores familiares, dentro del marco de una figura del mundo conocido; se establecen analogías con los términos conocidos.

Pero existe la gran limitante de que en el momento en que se entra en contacto con los rasgos profundos de la cultura ajena, los cuales simplemente no pueden caer bajo las categorías de lo "usual", estos aspectos pasan a constituir lo negativo, pues contradicen y niegan la figura de mundo conocido. Es su "reverso" y, por lo tanto, se ve como lo satánico, lo diabólico; aquello que pone en riesgo mi mundo, y por ello, debe ser destruido.

Precisamente por esta razón, Lázaro se instaura como la figura ajena y extraña por excelencia. No hay lugar para él en la concepción de mundo de los seres humanos que aún forman parte de la vida. En definitiva, es percibido como una alteridad inaceptable para los hombres que alguna vez lo conocieron.

Este infructuoso confrontamiento se refleja rotundamente en el texto de la escritora costarricense cuando se da el encuentro de Lázaro con la hetaira. En la oscuridad y el anonimato, sin palabras, se abrazan, se besan y ruedan por el suelo en una ambigüedad que no permite distinguir sus facciones. En este momento Lázaro siente que es posible que sus carnes, que aún están costrosas a muerte, revivan. Logra sentir y olvidar.-- ;Es posible estar vivo!--, piensa.

Sin embargo, llega el momento del reconocimiento. La hetaira que representa la cultura dominante en este caso, reduce la cultura ajena, es decir, a Lázaro que es el extranjero, el otro, a rasgos conformes con su figura de mundo, pero al no lograr 
hacerlo, no consigue percibir al otro como a su igual. No se permite escuchar al otro ni siquiera, por lo cual, será juzgado y calificado como inferior; generando pavor en la cultura que trate de asimilarlo, lo cual se refleja en la reacción de la hetaira:

De pronto ella se sobresalta, veo sus ojos aterrorizados fijos sobre mí.

- ¡Tú eres Lázaro! - dice su voz temblorosa mientras trata de cubrir su cuerpo desnudo.

No puedo negarlo y me encojo avergonzado.

Murmurando a media voz huye tratando de vestirse y con el terror en sus pupilas.

- ¡CCómo te atreves?! ¡¿Cómo te atreves?! - me grita de lejos.

Yo quedo postrado, lleno de reminiscencias, frustraciones, desengaños, maldigo a Jesús por haberme dado esta vida seca, desértica, sin esperanza (...) Mis puños golpean el suelo y maldigo una y mil veces este horror, esta desgracia sin nombre de ser el resucitado, el maldito del que todos se apartan con terror (Pinto, 2003, p. 83).

En el momento en que Lázaro resucita, se convierte en el único ser humano que se ha levantado de entre los muertos. En él aún se huele la muerte, la cual es la mayor fuente de dudas, temores y angustias que la humanidad ha enfrentado, pues a pesar de que es totalmente desconocida, desconcertante y terrible, es lo único inmanente en la vida.

Más adelante, cuando Lázaro ve que un grupo de niños que juegan, al percatarse de su presencia temen, reflexiona sobre el abismo que existe entre ambos ahora: "Quiero hablar, mentir, inventar una historia para que esos ojos me miren como antes, pero sé que es inútil; ellos sienten al enemigo cerca, se acurrucan uno al lado del otro, buscando protección" (Pinto, 2003, p. 58). 
Para finalizar, Villoro (1998) afirma que para lograr comprender al otro, cada cultura debe superar su marco de creencias básicas, transformarlo e invitar a la otra cultura a ocupar un lugar equivalente en su propio mundo, donde se respete tanto su igualdad como su divergencia.

En este caso, los seres humanos que aún no han experimentado la muerte, necesitan aceptar al Lázaro resucitado como un sujeto de derechos y de significados. Para lo cual, se debe reconocer su igualdad en su plena diferencia. Más aún si se toma en consideración que al rechazar a Lázaro se niega también la misma naturaleza humana y futuro de todo ser vivo, del que nadie puede escapar. Esta actitud es comprensible, sin embargo, pues a lo largo de la historia, el hombre siempre ha censurado todo aquello que no conoce y no existe mayor incógnita para la humanidad que lo que nos espera después de la muerte.

Nuestro amigo Lázaro se ha dormido y voy a despertarlo. (Juan 11, 11)

En un primer momento, el título de la novela de la escritora costarricense ( $E l$ despertar de Lázaro) comulga con la idea de que mientras se crea en Dios, no existirá la muerte. Así la muerte se percibe como un sueño que somete al sujeto hasta que llegue el momento de la resurrección; es decir, el momento del despertar.

Sin embargo, la resurrección no sólo constituye el despertar de un cuerpo que yace en el sepulcro. Se trata del despertar de una consciencia, de un espíritu que agoniza, que lucha entre el ser y el no ser. Acontecimiento que ejemplifica el protagonista de esta novela costarricense.

En el caso del Lázaro de Julieta Pinto, se evidencia que vive un doble exilio, el primer destierro que sufre subordina al segundo. Por tanto, se constituye como un ser que no pertenece a la vida ni a la muerte. Como resultado, no logra finalizar su periplo, lo cual provoca el desgarramiento su ser, un grave problema de identidad y la marginalización de todos aquellos con quienes se relacione. 
La verosimilitud de este Lázaro, a diferencia del bíblico, lo instaura como una persona de carne y hueso. Se trata de un hombre que siente, piensa, reflexiona, odia, se enfurece, pero ante todo asume la palabra y abandona el silencio que se le impone en la Biblia para relatar su versión de lo acontecido tras la resurrección.

Asimismo, gracias a la teoría del exilio y de la otredad, se comprueba que lo que sucede con Lázaro y su entorno es que se da una "no relación" con el otro. Se reconoce la presencia del otro, pero esta no es nunca aceptada en plenitud. La única forma que encuentran para soportarlo es que sea ignorado y temido a la vez.

Para finalizar, es indispensable desentrañar el significado de la resurrección en Lázaro. La resurrección deja en él una huella tan terriblemente profunda y tenebrosa que en lugar de afirmar su fe, la debilita, hasta el punto de la casi extinción. La resurrección es un hecho funesto para él. Constituye el doble exilio. Ya no pertenece a ninguna parte. Lázaro será por siempre diferente a los demás, por lo cual nunca formará parte ni de la vida ni de la muerte. Rechazo que expresa espléndidamente Julieta Pinto:

Quería tener un hogar y envejecer junto a una larga mesa rodeada de hijos. Ahora las mujeres bajan los ojos cuando las encuentro en mi camino y se niegan a escucharme si llamo a sus casas. A nadie le gusta un hombre que aún conserva en su mirada las costras del sepulcro y en su piel la pestilencia de la tumba (Pinto, 2003, p. 14).

De este modo, este texto literario hace una caracterización intensamente profunda del personaje principal, Lázaro de Betania, y la lucha que se lleva a cabo en su interior después de su resurrección. Presenta a un Lázaro lleno de dudas, frustraciones, temores, resentimiento e incluso de odio que es sometido a una experiencia desgarradora solo para que Jesús logre demostrar su poder en la 
tierra. Gracias a ello, Lázaro pierde su identidad y su ser. Se convierte en un ser exiliado, en la otredad.

No obstante, su reacción ante la resurrección que experimenta refleja, a diferencia de la versión oficial bíblica, a un ser humano de carne y hueso. Julieta Pinto saca a Lázaro de Betania de su eterno silencio y lo dota de voz para expresar sus más hondos pensamientos y sentimientos. Ese precisamente es el mayor logro del crudo despertar de Lázaro. 
1. Escritora uruguaya que desde 1972 se exilia en España y es considerada una de las autoras más importantes de la lengua española.

2. Obra literaria ganadora del XVIII Premio Internacional Unicaja de Poesía Rafael Alberti.

3. Escritor español que nace en 1964. Es licenciado en periodismo, dedicado a la novela histórica quien, además, ha escrito varios folletos informativos para la revista electrónica La verdad Católica.

Notas 
Culler, Jonathan. (1984). Sobre la deconstrucción Teoría y crítica después del estructuralismo. Madrid: Cátedra. Cp. II. Disponible en: http://www. jacquesderrida.com.ar/comentarios/culler.htm

De Peretti della Rocca, C. (1989). Jacques Derrida: Texto y deconstrucción. Barcelona, España: Editorial Antropos.

Martínez Fernández, J. (2001). La intertextualidad literaria (Base teórica y práctica textual). Madrid, España: Ediciones Cátreda, S.A.

Herrasti, Pedro. (2008). El cristiano ante la muerte. La Verdad Católica. № 633.

Disponible en: http://www.laverdadcatolica.org/ElCristianoAnteLaMuerte.htm

Hurault, Bernardo y Ricciardi, Ramón. (1972). La Santa Biblia. España: Editorial Verbo Divino.

Jones, Sonia. (2008). Entrevista sobre el texto El despertar de Lázaro de Julieta Pinto. Facultad de Letras. Universidad de Costa Rica, San Pedro, San José.

Peri Rossi, Cristina. (2003). Estado de Exilio. XVIII Premio Internacional Unicaja de Poesía Rafael Alberti. Madrid, España. Editorial: Visor Libros.

Pinto, Julieta. (2003). El despertar de Lázaro. San José, Costa Rica: Red Editorial Iberoamericana Centroamérica S.A.

Sciacca, M. (1962). Muerte e inmortalidad. Barcelona: Editorial Luis Miracle, S. A.

Villoro, Luis. (1998). Estadios en el Reconocimiento del Otro / La Alteridad Inaceptable. Estado plural, pluralidad de culturas. Universidad Nacional Autónoma de México. México: Editorial Paidós. 